\title{
Planejamento reformista-progressista, instrumentos urbanísticos e a (re) produção do espaço em tempo de neoliberalização. Uma exploração a partir do caso de Sáo Bernardo do Campo (Sáo Paulo)
}

Claudia-Virginia Cabral de Souza. Universidade Federal do ABC, Santo André, Brasil. Jeroen Klink. Universidade Federal do ABC, Santo André, Brasil. Rosana Denaldi. Universidade Federal do ABC, Santo André, Brasil.

RESUMO | Argumentamos que a maior articulação entre a teoria do planejamento e a economia política/geografia crítica a partir da leitura analítica dos conflitos sociais que acompanham o desenho e a execução dos instrumentos urbanísticos gera novo conhecimento sobre a neoliberalização urbana em países emergentes como Brasil. Desenvolvemos o raciocínio a partir de um estudo de caso sobre os limites e potencialidades do planejamento redistributivo-progressista na cidade de São Bernardo do Campo (Grande São Paulo), que simboliza a trajetória espacial, socioeconômica e política do regime desenvolvimentista brasileiro. A análise mostra que um governo local compromissado com as premissas do planejamento urbano inclusivo e com capacidade técnico-operacional para implementá-las, deparou-se com vários desafios. Ao mesmo tempo, o setor imobiliário mostrou notável capacidade para alavancar os mercados de terra e para preencher -ou esvaziar- os instrumentos urbanísticos associados a esses mercados, negando-lhes o caráter inerentemente progressista ou neoliberal-mercantil, conforme idealizado por muitos planejadores.

PALAVRAS CHAVE | planejamento urbano, governo local, mercado da terra.

ABSTRACT | We argue that a stronger linkage between planning theory and political economy/critical geography -through an analytical reading of the social conflicts that accompany the design and implementation of instruments of urban planning-provides additional insights to understanding urban neoliberalization in emerging countries such as Brazil. We develop this argument through a case study on the limits and potentials of progressive-redistributive planning in São Bernardo do Campo (Metropolitan São Paulo), which symbolizes the spatial, socio-economic and political trajectory of the Brazilian developmental regime. Our analysis shows that a local government, committed to the premises of inclusive urban planning, and with the available technical-operational implementation capacity, faced several challenges to do so. At the same time, the real estate sector showed a remarkable capacity to leverage land markets and to fill in -or hollow out- the associated planning instruments, thereby denying their inherently progressive-redistributive or neoliberal-mercantile character, as idealized by many planners.

KEYWORDs | urban planning, local government, land market. 


\section{Introduçáo}

Nos últimos anos multiplicaram-se os debates sobre a neoliberalizaçáo dos espaços urbanos via grandes projetos urbanos, parcerias público-privadas e outros mecanismos de empresariamento urbano, reescalonamento e reestruturação do Estado. A discussáo recebeu contribuiçóes principalmente dos campos da economia política e da geografia crítica acerca das relaçóes imbricadas entre a reestruturação econômica global, o esvaziamento do keynesianismo espacial -marcado por um projeto redistributivo de coesão sócio-espacial, sob a coordenação do Estado nacional- e a disseminação de estratégias de competividade urbana (Brenner, 2004; Harvey, 1989). Essa literatura proporcionou chaves analíticas para lançar luz sobre as contradiçôes urbanas na fase atual do capitalismo, como, por exemplo, as relaçóes entre Estado, escala e espaço na produção de segregação social nas cidades dos países centrais, em contextos de esvaziamento do regime de bem-estar social.

Apesar desses avanços, a pesquisa sobre neoliberalização urbana apresenta limites para dialogar com a complexidade e diversidade das dinâmicas territoriais e sociais que marcam as cidades no século xxi. Cabe primeiramente ressaltar que há tempo os estudos pós-coloniais e pós-estruturalistas expressaram dúvidas sobre a aplicabilidade de teorias gerais, normalmente elaboradas a partir do contexto dos países centrais (Robinson, 2010). Os poucos trabalhos no campo da economia política sobre a América Latina em geral, e o Brasil em particular, mostram que as especificidades geográficas e históricas das relaçóes entre o nacional-desenvolvimentismo e as cidades da região não apresentam uma analogia clara com o esvaziamento do keynesianismo espacial nos países centrais (Klink \& Souza, 2018). Mas o ponto que interessa ressaltar neste artigo é que a geografia crítica e a economia política, áreas de conhecimento que mais contribuíram para as pesquisas sobre neoliberalização urbana, apresentam leituras abstratas sobre a escalaridade e espacialidade do Estado, em geral, e sobre sua relação com a questão urbana, em particular. Encontram-se poucas abordagens sobre como as escalas são preenchidas (ou esvaziadas) pelos agentes a partir de suas percepçóes, narrativas e estratégias em relação aos instrumentos de política urbana. Curiosamente, embora o campo do planejamento urbano-regional esteja em posiçáo privilegiada para elaborar e complementar as análises sobre neoliberalização urbana, há pouco diálogo entre as vertentes, o que poderia proporcionar insights sobre o papel do planejamento e dos instrumentos urbanísticos no processo de reestruturaçáo do Estado em tempos de neoliberalizaçáo.

Cabe também destacar que as pesquisas sobre os Grandes Projetos Urbanos (GPUs) e o empresariamento urbano representam apenas uma faceta dessa discussão, considerando que a administração local não representa um bloco monolítico e é objeto de diversas pressóes sociais. Mais particularmente, movimentos sociais, proprietários de terra, empreendedores imobiliários e empresários industriais, entre outros, elaboram estratégias para influir sobre o desenho e a implementaçáo da política urbana. $\mathrm{Na}$ prática, isso significa que o resultado da política urbana não pode ser deduzido, ex ante, do caráter supostamente progressista-redistributivo ou neoliberal-mercantil dos próprios instrumentos urbanísticos. 
No entanto, há poucos estudos que articulam a investigação mais detalhada dos instrumentos urbanísticos a uma leitura analítica dos projetos, estratégias e percepçóes dos agentes públicos e privados que procuram influenciar o desenho e a implementação da política urbana e a atuação territorial do Estado em escala local (Brajato, 2015). Uma abordagem nessa linha abriria uma perspectiva de análise concreta acerca da dinâmica e política urbanas em meio a processos de neoliberalização. Autores como Robinson (2010), por exemplo, argumentam que as cidades frequentemente "inventam" as suas próprias estratégias e políticas. A teoria do planejamento urbano-regional pode iluminar a análise de como, e sob que circunstâncias, as cidades fazem isso a partir das percepçóes e estratégias adotadas pelos agentes no sentido de influenciar o desenho e execução dos instrumentos urbanísticos, frequentemente distanciando os eixos da política urbana "efetivamente existente" das suas premissas iniciais.

Nesse sentido, este artigo explora como as pesquisas sobre neoliberalização urbana podem ser enriquecidas a partir de uma mediação com a teoria do planejamento urbano e de uma leitura acerca das percepçóes e estratégias adotadas pelos agentes em relação aos instrumentos urbanísticos. Faremos isso a partir de um estudo de caso sobre política urbana em São Bernardo do Campo, cidade brasileira localizada na Região Metropolitana de São Paulo (RMSP). O caso brasileiro é um exemplo emblemático da complexidade dos entrelaçamentos de neoliberalização, reestruturação e reescalonamento do nacional-desenvolvimentismo e da trajetória contraditória dos espaços urbanos e metropolitanos.

A escolha de Sáo Bernardo do Campo (sBC) como estudo de caso sobre a aplicação de um conjunto de instrumentos justifica-se pelo papel central que a cidade, a indústria e as lideranças sociais -que tem seu expoente no ex-presidente Luís Inácio Lula da Silva (Lula) - desempenharam no projeto desenvolvimentista. De certa forma, compreender a trajetória da cidade e os limites e potencialidades da aplicação dos instrumentos urbanísticos regulamentados pelo Estatuto da Cidade (Lei n. 10.257, 2001) no pós-democratização do país gera insights acerca do próprio esgotamento do projeto social-desenvolvimentista no Brasil, o que presenciamos no período pós-2015. O estudo de caso baseou-se em pesquisa documental e, também, em dados secundários e entrevistas semiestruturadas com o ex-prefeito Luiz Marinho, gestores municipais, movimentos sociais, empresários e agentes do setor imobiliário.

Após esta introdução, o artigo estrutura-se em quatro seçóes complementares. Na primeira, discorremos sobre o Estatuto da Cidade e os instrumentos de política urbana. Na segunda, recuperamos, sinteticamente, a trajetória do desenvolvimento local, enquanto na terceira descrevemos o desenho e implementação da política urbana na gestão do ex-prefeito Luiz Marinho. Na quarta seção, com base em entrevistas, apresentamos a percepção dos atores e as estratégias efetivas adotadas pelos mesmos em relação aos instrumentos urbanísticos. Concluímos o artigo com os principais resultados do estudo de caso, incluindo elementos para a elaboraçáo de uma agenda de pesquisa sobre neoliberalização urbana com relevância para os países emergentes. 


\section{Estatuto da Cidade e instrumentos de política urbana}

A década de 1980 foi marcada pelo processo de redemocratização do país. Em meio a uma mobilização social inédita, os setores sociais progressistas relacionados à questão urbana apresentaram à Assembleia Nacional Constituinte uma Emenda Popular pela Reforma Urbana, obtendo, como resultado, o reconhecimento da função social da propriedade e do direito de posse dos moradores de favelas e periferias urbanas pela Constituição do Brasil (1988).

A mesma década deu lugar à reestruturação produtiva e à disputa entre dois projetos de desenvolvimento concorrentes - de um lado, a preservação e institucionalização de elementos do desenvolvimentismo, com abertura para processos participativos, e, de outro, a neoliberalização do Estado, que acabou por impor-se na década de 1990, apesar da conquista de direitos assegurada pela carta constitucional. Os anos 90 ficaram marcados pela reestruturação e pelo reescalonamento do Estado. O processo de neoliberalizaçáo desenvolveu-se por meio de movimentos instáveis e contraditórios de roll back -momento destrutivo, quando o Estado desenvolvimentista foi atacado de várias formas- e roll out, um momento criativo e proativo de (re) regulamentação (Souza, 2013). O roll back do Estado desenvolvimentista na década de 1990 levou à ampliação da crise social nas metrópoles, o que contribuiu para o roll out do desenvolvimentismo a partir de 2006, o que náo significou um rompimento radical com a trajetória de neoliberalização, mas ampliou os instrumentos redistributivos do Estado e priorizou o mercado interno, influenciando a distribuição de renda e a alocação de investimentos (Bastos, 2012). Apesar dos esforços neoliberalizantes dos anos 90, a redemocratização e a descentralização haviam institucionalizado a agenda da reforma urbana, por meio do Estatuto da Cidade (EC), que, aprovado em 2001, encontrou no governo Lula um ambiente favorável à sua implementação.

O Ec regulamentou a Constituição do Brasil (1988) e instituiu a nova política urbana nacional, fundada nos princípios da função social da cidade e da propriedade, direito à moradia e gestão participativa, os quais deveriam nortear a elaboraçáo e implementação dos planos diretores locais. Uma série de instrumentos urbanísticos redistributivos foram previstos e regulados pelo EC com o intuito de que os governos locais pudessem intervir nos mercados de terra, visando os interesses da coletividade. É o caso de instrumentos como as Zonas Especiais de Interesse Social (zEIs) e o Parcelamento, Edificação ou Utilização Compulsórios (PEUC) e seus sucedâneos legais -o Imposto Predial e Territorial Urbano (IPTU) Progressivo no Tempo- e a desapropriação com pagamento em títulos da dívida pública. Nesse sentido, pode-se dizer que o EC reflete o compromisso entre uma práxis mais radical, pautada pela queixa e reivindicaçáo de acesso à terra e à cidade, como espaço coletivo de geraçáo e apropriaçáo de riqueza, e uma prática de planejamento urbano estruturada nos pilares da racionalidade comunicativa, isto é, no rompimento com o planejamento tecnoburocrático e na assimilação do papel estratégico da participação popular (Healey, 2003) e da funçáo social da propriedade urbana (Law-Yone, 2007).

As zEIs restringem o uso do solo à Habitação de Interesse Social (HIs), voltada aos segmentos mais pobres. De início, na década de 1980, as ZEIs tinham como finalidade o reconhecimento da posse da terra e sua regularização e urbanização. 
Logo a seguir, foram criadas as ZEIS de vazios, visando a reserva de terras para a produção de HIs. Após sua inclusão no EC, as ZEIs foram previstas na maioria dos novos planos diretores e são hoje, um dos principais instrumentos de gestáo da política fundiária das grandes cidades (Oliveira \& Biasotto, 2011).

Por sua vez, o PEUC impóe aos imóveis urbanos ociosos a obrigação de promover o parcelamento do solo (no caso de glebas), edificar (no caso de terrenos vazios) ou ampliar a construçáo (caso de imóveis subutilizados) ou, ainda, utilizar, nos casos de edificaçóes desocupadas. Caso a obrigação não seja cumprida no prazo determinado, o imóvel sujeita-se à aplicação sucessiva do IPTU Progressivo no Tempo e da desapropriação com pagamento em títulos da dívida pública, cujo objetivo não é arrecadatório, mas o de indução ao cumprimento da função social da propriedade. A competência para determinar a implementação do PEUC e as condiçóes e prazos para cumprimento da obrigação foi atribuída pelo EC à lei municipal específica, com base no plano diretor, que, considerando as particularidades do território, deve definir as áreas passíveis de aplicação do instrumento, de forma a "evitar a retenção especulativa de imóvel urbano, que resulte na sua subutilização ou não utilização" (EC, art. $\left.2^{\circ}, \mathrm{VI}, \mathrm{e}\right)$. Ao combater a ociosidade dos imóveis urbanos, o PEUC contribuiria para conter o espraiamento e a dispersão da cidade. Embora regulamentado há mais de 15 anos e previsto na maioria dos planos diretores do pós-EC, as iniciativas de implementação do PEUC são raras e quase sempre interrompidas. Em apenas três municípios a aplicação não sofreu descontinuidade -SBC, São Paulo e Maringá (Paraná)-, como demonstrou recente pesquisa (Ministério da Justiça; Instituto de Pesquisa Econômica Aplicada, 2015).

Alguns autores acreditam que a aplicação conjunta de ZEIS e PEUC sobre um mesmo imóvel potencializaria seus efeitos (Denaldi, Brajato, Souza \& Frota, 2017; Rolnik \& Santoro, 2013), pois a combinação de um zoneamento restritivo com a obrigação de utilizar contribuiria, em tese, para ampliar a oferta de imóveis destinados à produção de HIs. Essa foi a intenção do Município de SBC ao associar a aplicação dos dois instrumentos.

Todavia, o EC regulamentou diversos instrumentos e dentre eles há os que podem ser utilizados para a maximizaçáo da renda fundiária urbana, destacadamente a Operação Urbana Consorciada (ouc), que articula o fundiário e o imobiliário ao mercado de capitais. Aprovado num momento em que os preceitos do neoliberalismo já estavam bastante difundidos, o texto legal é resultado da disputa e negociação entre os setores representativos do capital imobiliário e aqueles reunidos em torno do projeto de reforma urbana (Bassul, 2010).

As oucs constituem um tipo de parceria público-privada que tem como objetivo a renovação urbana de um setor da cidade, a ser viabilizada por meio da antecipação de recursos privados, em contrapartida à flexibilizaçáo dos parâmetros de uso, ocupação e edificabilidade vigentes na legislação urbanística municipal. Os recursos arrecadados devem ser aplicados exclusivamente na própria operação. Para sua utilização o instrumento deve ser previsto no plano diretor, sem prejuízo de que cada ouc seja aprovada por lei municipal específica contendo o plano da operação e a autorização para a emissão de Certificados de Potencial Adicional de Construção (CEPACs) pelo município. Os CEPACs são títulos mobiliários comercializados 
em leilóes da Bolsa de Valores de São Paulo, cuja rentabilidade está associada à valorização urbana, o que faz com que sejam considerados ativos de renda variável.

A literatura sobre o instrumento ressalta o contexto da neoliberalizaçáo e do avanço dos grandes projetos urbanos, concluindo que as oucs contribuem para a ampliação das desigualdades intraurbanas (Stroher, 2017). Para Fix (2009), o instrumento expressa o predomínio do complexo imobiliário-financeiro sobre os interesses dos cidadãos.

Em suma, observa-se que, via de regra, as análises tradicionais sobre os instrumentos urbanísticos ignoram que o Estado (os governos locais) não representa um bloco monolítico e é objeto de pressóes por parte dos diferentes segmentos sociais, que elaboram estratégias visando influir sobre o desenho e a implementação da política urbana. Na prática, isso significa que o resultado da política urbana náo pode ser deduzido, ex ante, do caráter supostamente progressista-redistributivo ou neoliberal-mercantil dos instrumentos de planejamento.

A literatura aponta que a aprovação do Estatuto gerou uma euforia exagerada no campo dos planejadores e movimentos sociais progressistas, que fetichizaram os instrumentos urbanísticos redistributivos (Brajato, 2015; Klink \& Denaldi, 2015). O balanço da implementação do EC mostra, no entanto, que frequentemente estes instrumentos são aplicados a partir de uma lógica contrária às premissas da função social da propriedade (Klink \& Denaldi, 2015; Santos Jr. \& Montandon, 2011). Por outro lado, com raras exceçóes, as ouc são interpretadas, a priori, como um instrumento de iniquidade social. Nesse sentido, argumentamos que o "urbanismo progressista" caiu numa armadilha metodológica ao atribuir forças inerentes aos instrumentos, dissociadas das relaçóes sociais, dos projetos e das estratégias dos agentes públicos e privados para "preencher" e dar conteúdo a esses instrumentos.

\section{São Bernardo do Campo: uma contextualização geográfica e histórica}

O município de SBC, com seus 408,8 km² e 827.437 habitantes (Instituto Brasileiro de Geografia e Estatística [IBGE], 2017), situa-se na Região do ABC, ou Sub-Região Sudeste da RMSP. Aproximadamente $85 \%$ de seu território corresponde a áreas ambientalmente protegidas: Área de Proteção e Recuperação de Mananciais da Represa Billings (APRM-B), responsável pelo abastecimento de água de parte da RMSP; e Parque Estadual da Serra do Mar, unidade de conservação de proteção integral.

A localização estratégica entre a cidade de São Paulo e o porto de Santos contribuiu para fazer do município a sede da matriz automobilística, instalada em meados do século xx, promovendo o desenvolvimento que levou a cidade a projetar-se no cenário econômico nacional. Ainda hoje SBC tem posição de destaque no conjunto dos 5.570 municípios brasileiros, ocupando, em 2015, a 16ª posiçáo no ranking do Produto Interno Bruto (РIB), que atingiu 42,745 bilhóes de Reais.

A instalação da indústria automotiva atraiu um acentuado movimento migratório em direção ao município. Por três décadas as taxas de crescimento populacional foram muito elevadas, fazendo com que a população crescesse mais de 16 vezes evoluindo de, apenas, 26.262 habitantes (em 1950) para 425.602 habitantes em 1980. O crescimento urbano correspondente a esse intenso ritmo de crescimento 
populacional fez-se, principalmente, por meio de loteamentos irregulares e precários, acompanhado pela formaçáo de favelas, onde as condiçóes de vida eram rudimentares. O fenômeno das favelas intensificou-se a partir dos anos 1960; em 1974, do número total de domicílios, $8 \%$ eram barracos de madeira (Maricato, 1977). Em 1980 os moradores em favelas correspondiam a 10,65\% da população total, percentual que atingiu 13\% em 1982 (Prefeitura do Município de São Bernardo do Campo [рмSвс], 1982), chegando a 20\% em 1987 (CDH, 1987, como citado em Royer, 2002, p. 137). Diante desses dados é possível afirmar que a cidade-símbolo do desenvolvimentismo e da modernização do país formou-se e cresceu com base na industrialização de baixo custo, na urbanização precária do território e na degradação ambiental, processos típicos da produção das cidades no capitalismo periférico (Maricato, 2011).

A década de 1970 foi marcada pela emergência de movimentos populares, que contribuíram para a construçấo de espaços políticos novos e novas práticas sociais (Sader, 1988). Nesse contexto, o Sindicato dos Metalúrgicos assumiu a vanguarda do "novo sindicalismo", que projetou a entidade no plano nacional e internacional a partir da greve de 1978 .

$\mathrm{Na}$ década de 1980 as contradições urbanas e ambientais, surgidas com a instalação da grande indústria, foram agravadas pela crise do Estado desenvolvimentista. Nas cidades fordistas da Região do ABC a redução das plantas fabris e a desconcentração industrial provocaram um enorme impacto sobre as condiçóes de trabalho. Afinal, o projeto desenvolvimentista dos anos 50 resultara na concentração dos setores de bens de capital e bens de consumo duráveis no Estado de São Paulo, tendo a Região do ABC, especialmente São Bernardo, como seu lócus privilegiado. A reestruturação produtiva implicou numa inversão dessa tendência, trazendo consigo perda significativa dos empregos industriais, sensível queda da arrecadação municipal e aumento significativo do número de favelas.

As favelas e loteamentos irregulares, cujas presenças já se destacavam nos anos 80 , continuaram crescendo nas décadas seguintes. Estudo realizado pela PMSBC em 2010 (PMSBC, 2010) estimou um déficit habitacional da ordem de 38.031 moradias para a populaçáo na faixa de renda de até 3 salários mínimos e identificou a existência de 261 assentamentos precários -favelas e loteamentos irregulares-, que abrigavam 35\% da população do município (IBGE, 2011). Grande parte desses assentamentos localizavam-se na APRM-B (151 assentamentos, sendo 68 favelas e 93 loteamentos irregulares). Apesar de ser uma área desfavorável à ocupação urbana, a APRM-B abrigava 26\% da população em 2010 (IBGE, 2011).

\section{O desenho da política urbana na administração Luiz Marinho}

Ao descrever a situação encontrada no início de seu governo, o então prefeito Luiz Marinho observou:

Cidade de contrastes (...), São Bernardo do Campo reúne uma imensa geração de riqueza, embora ainda persistam bolsóes de extrema pobreza. (...) Bairros se modernizam, empreendimentos imobiliários se multiplicam. Mas permanece a 
necessidade de lidar com a exclusão social, a pobreza, a precariedade habitacional, a baixa instrução e a ausência de qualificação profissional de contingentes importantes de nossos concidadãos. (PMSBC, 2010a, p. 9)

A partir de 2009, sob sua liderança, a cidade, que acumulava histórico déficit social, contou com uma ampliação considerável do volume de investimentos em infraestrutura urbana, habitação e políticas sociais e com iniciativas no campo do desenvolvimento econômico local. Articulado ao governo federal, o município desfrutou de uma inserção privilegiada no projeto social-desenvolvimentista da "era Lula-Dilma Roussef".

Necessário lembrar que Luiz Marinho, herdeiro do sindicalismo combativo da Região do ABC, havia sido presidente do Sindicato dos Metalúrgicos e da Central Única dos Trabalhadores, além de Ministro de Estado do Governo Lula. Eleito pelo Partido dos Trabalhadores, herdou, também, a experiência em políticas redistributivas que o partido desenvolvia no ABC desde o início da década de 1980. Seu programa de governo alinhava-se com a agenda da reforma urbana, analisada anteriormente, prevendo (i) a revisão do plano diretor e da legislação complementar, (ii) a urbanização, regularização fundiária e recuperação ambiental dos assentamentos precários, (iii) a elaboração do plano municipal de habitação, da lei regulamentadora das zEIs e das normas para produção de habitaçáo social, (iv) a identificaçáo dos vazios urbanos e sua gravação como zeIs destinadas à produção de HIs, e (v) a criação de um conselho de desenvolvimento urbano.

Logo em 2009, o governo municipal criou o Conselho da Cidade e do Meio Ambiente (ConCidade), reunindo os diferentes segmentos sociais para o debate das políticas de habitação, mobilidade, infraestrutura, saneamento, meio ambiente e controle do solo urbano. Com o acompanhamento deste Conselho, revisou-se o plano diretor vigente, pouco efetivo e apenas formalmente alinhado com o EC.

O novo plano diretor (Lei n. 6.184, 2011) instituiu um macrozoneamento que permite compreender a lógica da regulação e da aplicação dos instrumentos. Ele divide o território municipal em três compartimentos, definidos pelas bacias hidrográficas: Macrozona Urbana Consolidada (MUC), inserida numa bacia apta à ocupação urbana; Macrozona de Proteção e Recuperação dos Mananciais (MPRM), cuja denominação deriva de sua localização na APRM-Billings; e Macrozona de Proteção Ambiental (MPA), inserida em bacia ocupada, predominantemente, pelo Parque Estadual da Serra do Mar, unidade de conservação de proteção integral (Figura 1). As duas macrozonas ambientalmente protegidas (MPRM е MPA) correspondem a, aproximadamente, $85 \%$ do território de SBC, como informado anteriormente. 


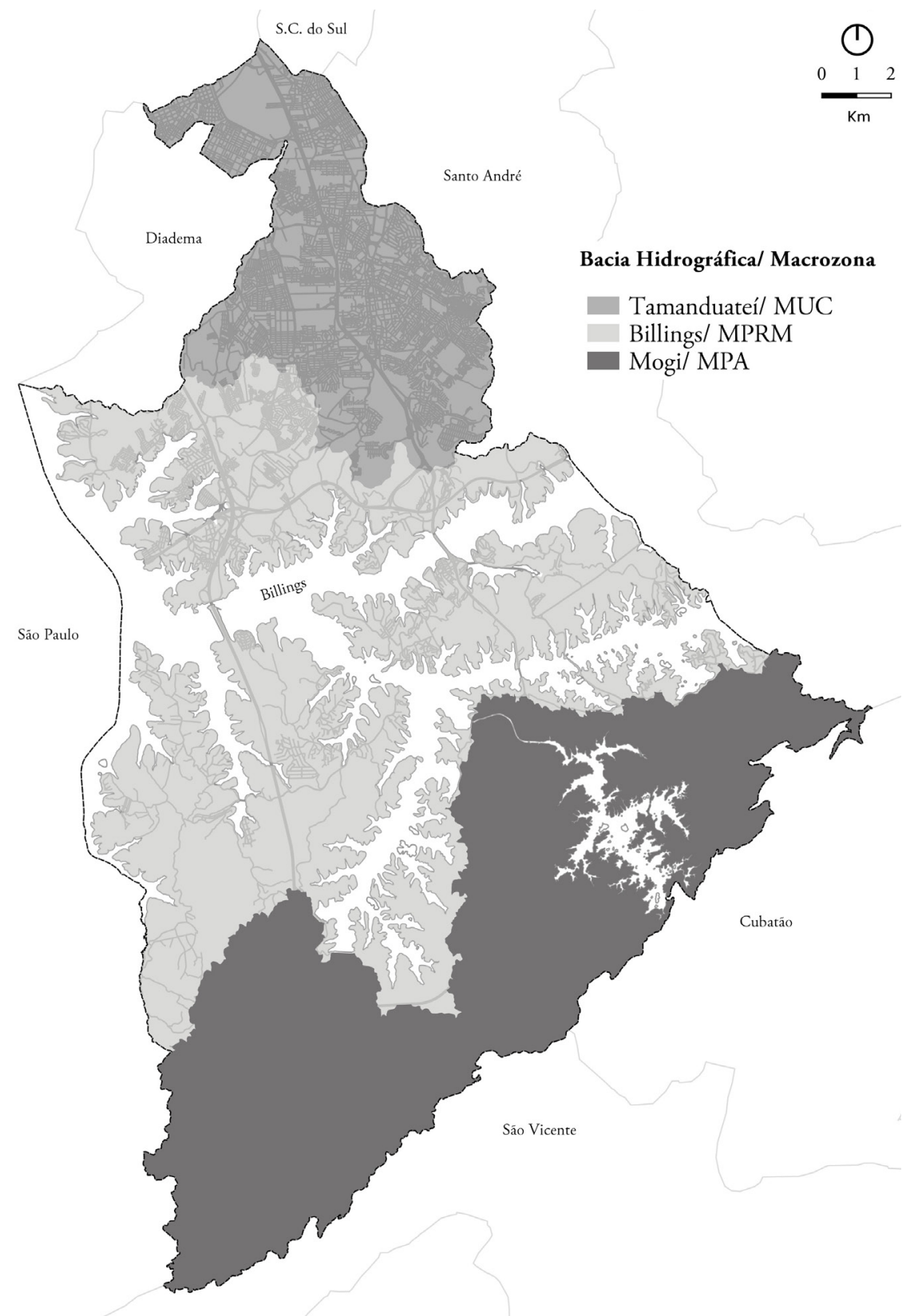

FIGURA I | Compatibilidade do Macrozoneamento (Lei n. 6184/2011) às bacias hidrográficas

FONTE: DEPARTAMENTO DE PLANEJAMENTO URBANO / PMSBC 
A rigor, apenas a MUC é favorável à ocupação urbana. Entretanto, a APRM vinha se adensando. Em função disso, o novo plano diretor instituiu o PEUC, com o objetivo de otimizar a ocupação do solo e combater a retenção especulativa de imóveis ociosos na MUC e contribuir para a desaceleraçáo da ocupação da APRM-B, onde o instrumento não é aplicável, uma vez que a função dessa área consiste na produção de água.

O plano diretor também delimitou e descreveu as denominadas zEIs de vazios (zEIs-2), as quais totalizaram 2,227 milhóes de metros quadrados de terra, aproximadamente, o suficiente para atender o déficit acumulado dentro dos assentamentos precários, considerado prioritário.

Às ZEIS-2 demarcadas na MUC o plano diretor determinou a aplicação do PEUC, ${ }^{1}$ considerando tratar-se da parcela urbanizada do território, onde a terra é escassa e, em consequência, intensamente disputada e valorizada. A expectativa dos gestores municipais era de uma mudança na conduta dos proprietários, que viesse a resultar na disponibilização de terra para a produção de habitação de interesse social.

A aplicação do PEUC em SBC foi iniciada em 2013. Até novembro de 2016 foram expedidas 229 notificaçóes (correspondentes a pouco mais de 2,3 milhóes de metros quadrados), das quais 162 permaneciam válidas (1,25 milhóes de metros quadrados). Foram emitidas 30 notificaçôes para imóveis em ZEIs-2, das quais apenas sete $(23 \%)$ resultaram na aprovação de projetos habitacionais; entretanto, em área, os sete imóveis totalizam $392.541 \mathrm{~m}^{2}$ ou $47 \%$ do total de $829.382 \mathrm{~m}^{2}$ de ZEIS-2 notificadas (PMSBC, 2016).

A partir de 2015 iniciou-se a aplicação do IPTU Progressivo no Tempo, com base no EC e na Lei n. 6.324 (2013). A progressividade foi estabelecida pela duplicação das alíquotas do imposto (o máximo permitido pelo EC) em cinco operações sucessivas e cumulativas até o limite de $15 \%$, enquanto perdurassem as condiçóes que ensejaram a notificação. Assim, os imóveis notificados no ano de 2013, que até novembro de 2014 não haviam cumprido a obrigação imposta pelo PEUC, sofreram o lançamento da progressividade no exercício seguinte (2015), duplicando-se as alíquotas do imposto.

Desde então, observa-se que o IPTU Progressivo é um forte indutor ao atendimento da exigência legal: dos 27 imóveis enquadrados na progressividade em 2015, 18 (2/3) cumpriram a obrigação ao longo do exercício de 2015 e apenas nove não o fizeram. Em 2016 o percentual de atendimento das exigências legais no pós-lançamento da progressividade reduziu-se, ${ }^{2}$ mas ainda assim pode ser considerado significativo: dos 65 imóveis enquadrados -9 pela $2^{\text {a }}$ vez e 56 pela $1^{\text {a }}$ vez-, 27 $(41 \%)$ atenderam às exigências legais. No exercício de 2017 foram submetidos ao instrumento 65 imóveis: 27 pela $1^{\text {a }}$, 34 pela $2^{\text {a }}$ e 4 pela $3^{\text {a }}$ vez.

Outra alteraçáo constante do plano diretor consistiu na reduçáo dos coeficientes de aproveitamento do solo na MUC, com o objetivo de compatibilizar o

$1 \longdiv { O }$ pEUc foi aplicado sobre os imóveis com área igual ou superior a $1.000 \mathrm{~m}^{2}$ não edificados e subutilizados (aqueles que não atingem o coeficiente de aproveitamento mínimo de $20 \%$ da área do terreno) e às edificações não utilizadas com área igual ou superior a 500 metros quadrados.

2 A redução das respostas positivas deu-se, provavelmente, em funçáo das expectativas de alternância dos gestores e consequente redirecionamento da política urbana municipal. 
adensamento urbano com a infraestrutura instalada. A isso foi associada a possibilidade de obtenção de potencial construtivo adicional mediante a aplicação de outorga onerosa do direito de construir, instrumento relacionado à captura da valorização imobiliária e ao financiamento da cidade.

Por outro lado, o mesmo plano diretor instituiu a possibilidade de realização de operaçóes urbanas consorciadas (ouc), que, como mencionado anteriormente, é um instrumento polêmico. Foi delimitada uma grande "mancha", reunindo vários bairros, inclusive o centro da cidade, como área onde o instrumento poderia ser aplicado. Posteriormente ao plano diretor foi desenvolvido o projeto da OUC-SBC, que ampliou ainda mais a área de abrangência do instrumento.

A ouC-SBC, aprovada pela Lei n. 6.403 (2015), perfaz $26 \mathrm{~km}^{2}$, que a tornam, na visão da empresa de consultoria responsável pela modelagem da maioria das operaçôes brasileiras, a maior operação urbana projetada no país. Abrange a área de maior valorização e interesse imobiliário no município, que representa $95 \%$ do Valor Geral de Vendas (vGv) dos lançamentos imobiliários no período entre 2006 e 2010, adotado como referência para elaboração do estudo de viabilidade. Seu polígono foi recortado segundo a área de influência de uma nova linha do Metrô da cidade de São Paulo (em projeto), que fará a conexão de SBC com a rede de transporte de passageiros por trilhos da capital.

A administração municipal apresentou duas justificativas para o desenvolvimento da OUC-SBC: (i) ela seria um mecanismo que possibilitaria à municipalidade recuperar parte da valorização decorrente da implantação futura linha de transporte coletivo, evitando que toda ela fosse apropriada unicamente pelos proprietários e promotores imobiliários e (ii) geraria recursos não-tributários para projetos pontuais, em especial a renovação do centro da cidade, liberando o orçamento geral para aplicação em outros investimentos. A administração adotou a narrativa, bastante disseminada, de que as oucs seriam autofinanciáveis (Fix, 2004).

No entanto, anteriormente à aprovação da lei, no governo Luiz Marinho, a área de abrangência da OUC-SBC recebeu investimentos públicos das três esferas de governo, que, somados, chegavam a 1,6 bilhão de reais (em 2015), dos quais cerca de $90 \%$ eram relativos a obras de infraestrutura, mobilidade urbana e drenagem, o que contribuiu para valorizar ainda mais a área e potencializar a ouc, projetada para captar em torno de 2 bilhôes de reais ao longo de 15 anos. As transformaçóes estruturais da área, garantidas por recursos públicos, em tese, atrairiam o investimento privado na ouc, condicionados à exceção da legislação de uso e ocupação do solo vigente, mediante a compra de CEPACs.

Com relação à destinação dos recursos auferidos, a lei prevê que 25\% do total devem ser utilizados em "desenvolvimento de ações de interesse social e inclusão urbana”. Os demais 75\% dos recursos devem ser divididos entre as obras de renovação do centro e obras pontuais e esparsas distribuídas na área da OUC-SBC.

Seguindo a modelagem adotada pelo projeto da ouc Porto Maravilha, desenvolvida na área portuária do Rio de Janeiro, a OUC-SBC autoriza a criaçáo de uma empresa pública de economia mista, que promove o desenvolvimento da ouc, e prevê a possibilidade de realização de Parcerias Público-Privadas, de gestão de ativos patrimoniais e serviços públicos e, ainda, a participação, como cotista, de Fundos de 
Investimento Imobiliário, entre outras responsabilidades delegadas pela prefeitura à sociedade de economia mista.

A implementação da OUC-SBC acabou por não acontecer. O último ato, realizado em 2016, no final da gestão Luiz Marinho, foi o início da tramitação do prospecto da ouc junto à Comissão de Valores Mobiliários (CVM) para análise e posterior autorizaçáo de realizaçáo do leiláo na Bolsa de Valores, o que náo chegou a ocorrer.

\section{Percepçáo, projetos e estratégias dos atores}

\section{Universo das entrevistas}

Realizamos 20 entrevistas, distribuídas entre: (i) quatro gestores municipais; (ii) seis proprietários de imóveis notificados pelo PEUC; (iii) três cooperativas habitacionais; (iv) dois corretores imobiliários; (v) duas entidades representativas do setor imobiliário e (vi) três conselheiros do ConCidade, representantes dos setores acadêmico, empresarial e do movimento popular.

Com relação aos gestores municipais, foram entrevistados, além do ex-Prefeito, a ex-secretária de Habitação e um consultor de operaçóes urbanas consorciadas. As cooperativas habitacionais, entrevistadas por meio de suas lideranças, foram selecionadas por terem adquirido terrenos em ZEIs-2 notificadas para desenvolver projetos habitacionais no âmbito do Programa Minha Casa Minha Vida-Entidades (PMCMV-E). Os corretores imobiliários por transacionar imóveis em ZEIS-2 e atuar junto às cooperativas habitacionais. Uma das entidades representativas do setor imobiliário é o Sindicato das Empresas de Compra, Venda, Locação e Administração de Imóveis Residenciais e Comerciais de São Paulo (sECovi-sP), com atuação estadual; a segunda é a Associação dos Construtores, Imobiliárias e Administradoras do Grande $\mathrm{ABC}(\mathrm{ACIGABC})$, que atua na Região do $\mathrm{ABC}$ e é referência em São Bernardo do Campo.

A definição dos proprietários de imóveis notificados a serem entrevistados observou dois critérios: as características do imóvel -zona, bairro, classes de notificação e ter sofrido, ou náo, o lançamento da progressividade - e o perfil do proprietário- Pessoa Física (PF) e Pessoa Jurídica (PJ). O setor imobiliário detém mais da metade das notificaçóes dirigidas a PJs notificadas, o que justifica a seleção de quatro empresas para entrevistas. Duas -as empresas 'A' e 'B'- são sociedades familiares que exercem as atividades de incorporação, construção e vendas e destacam-se como as maiores empreendedoras imobiliárias (em volume de produção) sediadas no $\mathrm{ABC}$; têm grande influência e conhecimento do mercado imobiliário regional. As duas outras têm seus imóveis em zeIs-2, sendo que a empresa 'c' é de pequeno porte e atua como construtora e administradora de bens próprios, enquanto que a empresa ' $D$ ' exerce, exclusivamente, a funçáo de administradora de bens próprios distribuídos em vários estados brasileiros.

\section{Estratégia do setor imobiliário em relaçâo à terra}

Nos últimos anos, especialmente depois da abertura de capital das grandes construtoras e incorporadoras imobiliárias na Bolsa de Valores, essas empresas adotaram a estratégia de formação de bancos de terra como uma forma de garantir aos 
investidores a valorização dos seus ativos. Tal estratégia difundiu-se no período do boom imobiliário e foi adotada por empresas de médio porte, as quais aderiram à iniciativa de formação de estoques de terrenos, motivados pela disponibilidade de crédito imobiliário. Os municípios do ABC e São Bernardo do Campo, em particular, não fugiram à regra. O setor imobiliário é predominante no universo dos proprietários de imóveis notificados pelo PEUC, concentrando, em suas mãos, um considerável quantitativo de terras: mais de meio milhão de metros quadrados, que representam $43,3 \%$ da área total notificada.

Somente a empresa 'в' possui cerca de 800 mil metros quadrados de terra em sBC, o que constitui $47 \%$ do land bank que a empresa informa em seu sítio eletrônico (mais de 1,7 milhão de metros quadrados). Isso corresponde a, aproximadamente, $1 / 3$ da reserva de terra demarcada como zeIs-2 no plano diretor do município. Curiosamente, a estratégia de reserva de terra não é assumida pelo presidente da empresa, que afirma não produzir estoque, pois, segundo ele, a contínua compra de imóveis contribui para a reprodução do ciclo de "aquisição/produção/venda"; assim, o processo permanente de aquisiçâo de imóveis é visto como uma atividade essencial, sem interesse especulativo, uma vez que a terra representa matéria prima para a produção. No entanto, o discurso produtivista bem elaborado não encontra ressonância na prática. ${ }^{3}$

Diferentemente, o dirigente da empresa 'A', que também dispóe de um volume de terras significativo, segundo dados da Secretaria de Finanças de SBC, expôs de forma franca sua estratégia de formação de um estoque de terras:

Eu adoro terreno. Eu me sinto bem. (...) Época de crise, o que estamos fazendo? A gente está comprando terreno. (...) Vão falar: 'esse cara é louco, numa época de crise dessa!' Mas é nessa época que estou comprando, e por quê? Porque o preço dos imóveis baixou muito, os preços estão lá embaixo (...), então estou comprando terreno hoje pra obras que vão ser feitas daqui a 5, 10 anos, 15 anos.

\section{Reaçôes ao PEUC e às ZEIS}

Um primeiro resultado que emerge das entrevistas é a relativa facilidade com que os agentes do "mercado" (isto é, parcela significativa dos proprietários notificados, as entidades empresariais e os corretores especializados) incorporaram os instrumentos considerados redistributivos -PEUC, IPTU Progressivo e ZEIS- nas suas estratégias discursivas e materiais.

Tentar "escapar" do instrumento é uma das estratégias empregadas pelos proprietários atingidos pelo PEUC e por aqueles cujos imóveis foram demarcados como ZEIS-2, o que foi observado, também, em outros casos (Brajato, 2015). Em SBC foram usados vários meios nesse sentido: negar-se a receber a notificação, solicitar prorrogação do prazo de um ano para apresentação de projeto (alegando dificuldades diversas, principalmente a crise econômica a partir de 2016), recorrer a projetos apresentados anteriormente para o imóvel (já arquivados ou indeferidos), promover

Para ilustrar, o imóvel de propriedade da empresa notificado pelo PEUC, um terreno vazio há vários anos, foi ocupado por um movimento de moradia em 2017, após a realizaçáo da entrevista. 
o desmembramento do lote antes de a notificação ser averbada em cartório, solicitar alvará de funcionamento para atividade provisória ou cuja instalação demandasse poucos recursos (como estacionamentos, por exemplo), entre outras tentativas de escapar do instrumento. Muitos recursos administrativos, elaborados por escritórios de advocacia, questionaram o instrumento em seus fundamentos, isto é, buscaram, com base numa interpretação equivocada da lei federal, insistir numa concepção de direito de propriedade quase absoluto, que nega a função social, como foi expresso no depoimento da assessora jurídica que acompanhava o diretor da empresa ' $D$ ' em sua entrevista:

De fato, eu entendo como um absurdo estar mexendo no direito de propriedade. Essa imposiçấo de construir é muito ruim. (...) Eu, avaliando como operadora de Direito, acho que isso é abusivo da parte do poder público, é como estar banindo o direito de propriedade. Tudo bem que a gente está sob a égide do interesse social, do bem comum, mas acho que isso extrapola o meu direito como proprietário de deixar aquela área ali parada, desde que não traga prejuízo aos vizinhos. De deixar ali latente até o momento que for oportuno vender.

Via de regra, mesmo quando implementadas isoladamente pelos municípios, as ZEIS enfrentam reaçóes por parte dos proprietários: a mais comum é manter o imóvel ocioso, sem função social; outra, é pressionar politicamente para que o zoneamento especial seja alterado. Em SвC о segundo tipo de reação ocorreu algumas vezes, como admitiu o ex-prefeito em sua entrevista, quase sempre casos em que o proprietário alegava interesse em instalar uma atividade econômica no local. No entanto, o discurso dos empresários do setor imobiliário é unanimemente favorável às ZEIs.

Já com relaçáo ao PEUC as opiniôes divergiram e a maior parte dos entrevistados disse discordar da aplicação do instrumento. Uma exceção é a empresa 'B', que se referiu ao PEUC e ao IPTU Progressivo como instrumentos inteligentes que inibem a especulação imobiliária que "distorce, de certa forma, o uso social da área". No entanto, este empresário reprovou a sobreposição de ZEIS e PEUC a um mesmo imóvel, com o argumento de que tal coisa "amarra" e pode inviabilizar o aproveitamento do bem. Assim como ele, com uma única exceção, os demais empresários entrevistados contestam a dupla gravaçáo. ${ }^{4}$ Para a empresa ' $C$ ', que tem dois imóveis em ZEIs-2, isso gera uma dupla pressão, o que é injusto diante da recessão do mercado. Mais enfática, a empresa 'A' refere-se aos instrumentos, articulados ou isoladamente, como uma "parafernália" que constrange o setor imobiliário e deve ser eliminada.

Por outro lado, vários entrevistados do mercado relativizaram a possibilidade de lançamento da progressividade do IPTU. A empresa 'D', por exemplo, náo apresentou

4 A única voz discordante é a do representante do secovi, para quem, do ponto de vista do setor imobiliário, Peuc/iptu Progressivo é desejável, uma vez que, segundo ele, os empreendedores imobiliários não têm interesse em especular e, sim, em produzir. Desse modo, a dupla gravação provocaria a disponibilização dos imóveis, ampliando a oferta e contribuindo para melhores “oportunidades de negócio”. Porém, essa separação dos agentes -o proprietário e o empreendedoré cada vez menos usual nas grandes cidades. Em SBC, como já vimos, a maior parte das terras vazias e subutilizadas pertence a empresas do setor imobiliário. 
recurso contra o lançamento, apostando na falta de agilidade da prefeitura e nas mudanças políticas durante o processo complexo de desenhar e aplicar o referido instrumento:

Isso aí a gente vai tratar com a prefeitura, vamos tentar negociar um parcelamento incentivado, como já aconteceu aqui várias vezes. $\mathrm{O}$ órgão público não tem a celeridade da iniciativa privada, não é verdade? A gente já foi beneficiada por prescrições, tem muita coisa prescrita, sabe?

Sobre a efetividade da conjugação de zEIS e PEUC para produção de HIs, os discursos reiteraram a importância do financiamento e da localização. Os próprios dirigentes das cooperativas habitacionais reconhecem uma inflexão na estratégia dos proprietários de terra e dos empreendedores em relação às ZEIS a partir do lançamento do PMCMV, que propiciou a articulação do instrumento ao financiamento. Nas palavras de uma das lideranças:

... era uma movimentação no campo da direita para que as áreas deles não fossem transformadas em AEIS... (...) aí nesse período a terra era mais barata, mas, mesmo sendo mais barata naquela época, a gente se esforçava para comprar e nem sempre conseguia viabilizar projetos... (...) num determinado momento isso inverteu, os donos vinham pedir para transformar em AEIs. E, quando veio o MCMV, aí era dinheiro garantido, a AEIs se valorizou porque aí você sabe que aquela área se enquadra no programa nacional, que tem potencial...

Outro dirigente de cooperativa habitacional, avaliando a importância da aplicação conjunta dos dois instrumentos, foi enfático quanto à simbiose perfeita entre as ZEIS e o funding: "Eu ainda acho que o instrumento é importante, mas se ele for complementado com o financiamento. Sem isso, a chance das zEIs ficarem inócuas é grande".

Os gestores confirmam que a viabilidade de produção de HIs relaciona-se, também, com a localização e o preço da terra e apontam os desafios estruturais que cercam o desenho e a implementação de instrumentos como as ZEIs. O depoimento da ex-Secretária de Habitação, Tassia Regino, evidencia a relação entre localização, preço e viabilidade de empreendimentos para a baixa renda:

Não se pode desprezar o preço da terra. Tem áreas pequenas que a gente gravou como ZEIS-2 na região mais central, porque estava mais próximo de alguns déficits mais específicos, mas é muito pouco provável que elas se viabilizem. (...) O preço da terra, mesmo considerando os instrumentos das zeIs e do PEUC, não pode ser secundarizado para que elas possam ser colocadas no mercado. (...) Não desgravamos nenhum terreno de zeIs-2 onde havia perspectiva, ainda que longínqua, de utilização e os que a gente desgravou foi dentro dessa lógica de disputa do território. Alguns eu concordei em desgravar porque, de verdade, não tinha nenhuma perspectiva de fazer alguma coisa naquela região. A gente ia "peitar" um negócio que de alguma forma beneficiaria a cidade, sem a menor perspectiva de resolver o nosso próprio problema. 
Um dos corretores que se especializaram na viabilização de terrenos para que as cooperativas habitacionais desenvolvessem projetos financiados pelo PMCMV-E, também entende que "as zeIs são necessárias, mas não nas regióes centrais, porque aí não 'vira', justamente por causa do preço".

\section{Reaçóes à OUC-SBC}

Observou-se que o mercado, diferentemente do que afirma a literatura acadêmica crítica, é reticente com relação ao instrumento. As entrevistas expuseram dúvidas acerca da viabilidade das oucs, além de questionamentos e posicionamentos contrários ao instrumento no meio empresarial.

A empresa 'B' alega que o instrumento não se adequa à escala do município e ao perfil dos potenciais compradores de imóveis, uma vez que

SBC não é São Paulo, não chega nem perto de São Paulo (...) e pagar CEPAC significa colocar muito dinheiro além do valor do terreno e eu náo sei se isso comporta no valor final de venda. (...) Eu acredito que náo deve pegar em SBC porque o preço final do produto aqui na região é muito barato; em São Paulo cabe...

Esse mesmo depoente considera que o CEPAC não é um bom investimento, já que quase não tem mercado secundário. ${ }^{5}$ Assegura que náo compraria CEPACs em um eventual leilão da OUC-SBC, pois como não atua apenas nesse município ampliaria sua produção em outras cidades. A empresa 'A', por sua vez, critica o preço do CEPAC da OUC-SBC, que julga muito elevado, enquanto que o representante de uma das entidades empresariais questiona as vantagens comparativas do instrumento em relação à tradicional outorga onerosa do direito de construir (oODC):

Apesar da gente falar de financeirização do mercado imobiliário, o produtor imobiliário ele é muito conservador, quer ter segurança. E ele tem segurança se estiver na lei uma tabela que informe que se ele comprar um terreno aqui e aprovar um projeto aqui ele sabe que vai pagar tanto de outorga onerosa. Não quer correr risco de ir para um leiláo e nem saber o que pode acontecer nesse leilão.

Por outro lado, os movimentos populares presentes no ConCidade náo manifestaram discordância com relaçáo ao emprego do instrumento e aquiesceram à antecipaçáo de recursos prometida pelo instrumento.

Em síntese, num contexto marcado pela escassez da terra e pelas disputas em torno do ideário da função social da propriedade, o pêndulo favoreceu os proprietários de terra, os construtores e incorporadores. Nas palavras de um dos dirigentes de cooperativas habitacionais:

... infelizmente, o mercado imobiliário usou melhor os instrumentos do Estatuto da Cidade do que a gente pensava, eles se adaptaram muito mais rápido, conseguiram utilizar os instrumentos que contribuíam com eles e os instrumentos que contribuíam para o acesso à cidade, para a função social da propriedade, esses não tiveram o resultado que a gente esperava. 
Diferentemente do mercado, os gestores municipais não encontraram a mesma facilidade no desenho e na aplicação dos instrumentos, o que remete às estratégias empresariais de moldar os instrumentos de acordo com os seus interesses e projetos específicos, conforme analisamos anteriormente. Além disso, é inegável a complexidade associada ao desenho e à aplicação de uma política territorial redistributiva no contexto da trajetória urbana contraditória de São Bernardo de Campo, que gerou uma cidade social e ambientalmente comprometida, onde a escassez de terra e os altos preços fundiários-imobiliários se fazem particularmente presentes, em função de décadas de industrialização e urbanização de baixos custos, sintetizadas anteriormente.

\section{Consideraçóes finais}

Neste artigo argumentamos em favor de uma maior articulação entre a economia política e a geografia crítica, de um lado, e a teoria do planejamento (por meio de uma leitura das percepçóes e estratégias adotadas pelos agentes em relação aos instrumentos urbanísticos), de outro, nas discussôes sobre neoliberalização urbana. Enquanto as abordagens da economia política generalizaram as contradiçóes urbanas associadas à reestruturação do Estado, o urbanismo gerou uma visão "essencialista/ fetichista" dos instrumentos urbanísticos, sem relacioná-los ao Estado e à atuação dos agentes. Nesse sentido, a análise crítica dos instrumentos aqui realizada, incorporando as percepçóes e estratégias dos agentes, proporciona uma mediação para evitar uma visão simplista das cidades como meros receptáculos dos processos de neoliberalização urbana. Dessa leitura do urbano como questão escalar-relacional, isto é, como uma arena na qual os agentes sociais disputam a hegemonia sobre a política local, em geral, e sobre a forma de preencher e direcionar os instrumentos urbanísticos, em particular, emerge uma cidade mais complexa cuja estratégia efetivamente existente frequentemente distancia-se dos princípios norteadores da política urbana.

A análise mostrou que o mercado possui facilidade em fazer a leitura dos instrumentos -tanto os de perfil supostamente progressista-redistributivo, quanto os liberais-mercantis- de acordo com seus projetos empresariais; ignora, contesta ou posterga a aplicação dos instrumentos quando estes não lhes interessam, ao mesmo tempo em que aproveita as linhas de crédito que acompanham a política urbana. Nesse cenário, a força dos agentes imobiliários coloca em xeque as teses "essencialistas", defendidas por muitos urbanistas, que atribuem sentido predeterminado aos instrumentos. Por exemplo, no caso da aplicação do PEUC em ZEIs, não pode ser descartada a hipótese de que a baixa adesão do mercado desencadeie uma efetiva redução da oferta de projetos e pressão sobre os preços fundiários-imobiliários no curto prazo. Não é objeto deste artigo investigar os preços imobiliários, mas foi consenso entre os agentes do mercado entrevistados que a combinaçáo dos instrumentos PEUC e zeIs inviabilizaria o aproveitamento do terreno. Ao mesmo tempo, o conservadorismo do mercado imobiliário em sBC em relação às Operaçóes Urbanas Consorciadas, além do valor do CEPAC proposto na lei municipal, poderiam inviabilizar o sucesso do instrumento em termos da estratégia de antecipaçáo de recursos, requalificação e valorização da área. 
A administração do prefeito Marinho, embora formalmente comprometida com as premissas da reforma urbana -planejamento progressista-redistributivo e participativo- e dispondo de capacidade técnico-administrativa favorável (quando comparada com a da maioria dos municípios brasileiros), se deparou com desafios para avançar na implementação de uma política urbana redistributiva. Esse quadro náo se deve apenas à agilidade do mercado, mas também se relaciona com o desafio de romper uma lógica de produção do espaço que gerou uma trajetória urbana comprometida e marcada pela escassez de terra, pela prática de altos preços fundiários-imobiliários e pela ausência de um movimento de moradia forte na cidade. No que se refere ao movimento de moradia, apesar dos avanços na articulação da ZEIS com o PMCMV-Entidades, este também sofreu com a pressão sobre os preços fundiários em função da capitalização parcial do subsídio do programa na renda da terra, além da cobrança de altos ágios na negociação do pagamento parcelado na aquisição dos terrenos pelas cooperativas.

A análise aqui desenvolvida gera possíveis subsídios para uma agenda de pesquisa sobre as relações imbricadas entre planejamento progressista, instrumentos urbanísticos e neoliberalização urbana em países emergentes como o Brasil. O cenário brasileiro atual, marcado pela crise econômica e pelo esgotamento do regime social-desenvolvimentista do período 2003-2015, aponta para uma nova fase de políticas de austeridade fiscal, com prováveis consequências sobre a política urbana e o desenho e a implementação dos instrumentos urbanísticos. Nesse sentido, cabe investigar não apenas como as cidades lançam mão de novos instrumentos (a exemplo das várias modelagens de parcerias público-privadas), mas também como redesenham os instrumentos existentes, priorizando a arrecadação adicional, possivelmente em detrimento de uma política urbana alinhada com as premissas da função social da propriedade. Por fim, o nosso estudo de caso mostrou um quadro desafiador, em que uma cidade metropolitana do Sudeste brasileiro, com capacidade técnico-administrativa, viu-se comprometida por uma trajetória urbana contraditória, que gerou altos preços fundiários e escassez de terra. É necessário avançar em pesquisas sobre cidades interioranas e não-metropolitanas localizadas em outras macrorregióes brasileiras, com dinâmicas territoriais-imobiliárias diferenciadas e com maiores fragilidades na capacidade técnico-administrativa.

\section{Referências bibliográficas}

Bassul, J. R. (2010). O Estatuto da Cidade: A construção de uma lei. Em C. S. Carvalho \& A. Rossbach (orgs.), O Estatuto da Cidade: Comentado (pp. 71-90). São Paulo, Brasil: Ministério das Cidades/Aliança das Cidades.

Bastos, P. (2012). A economia política do novo-desenvolvimentismo e do social desenvolvimentismo. Economia e Sociedade, 21 (N. especial), 779-810. http://dx.doi. org/10.1590/S0104-06182012000400004 
Brajato, D. (2015). A efetividade dos instrumentos do Estatuto da Cidade: O caso da aplicaçáo do Parcelamento, Edificação ou Utilização Compulsórios no Município de Maringá (PR). (Dissertação de Mestrado em Planejamento e Gestão do Território, Universidade Federal do ABC, São Bernardo do Campo, Brasil). http://bdtd.ibict.br/vufind/Record/ UFBC_f840762bb53261d91215402870162cca

Brenner, N. (2004). New State Spaces: Urban Governance and the Rescaling of Statehood. Oxford: Oxford University Press.

Constituição da República Federativa do Brasil de 1988 (1988). http://www.planalto.gov.br/ ccivil_03/constituicao/ConstituicaoCompilado.htm

Denaldi, R., Brajato, D., Souza, C. \& Frota, H. (2017). A aplicação do Parcelamento, Edificação ou Utilização Compulsórios. urbe: Revista Brasileira de Gestão Urbana, 9(2), 172-186. http://dx.doi.org/10.1590/2175-3369.009.002.ao02

Fix, M. (2004). A "fórmula mágica" da parceria público-privada: Operaçôes urbanas em São Paulo. Em Maria Cristina Schicchi \& Dênio Benfatti (orgs.), Urbanismo: Dossiê São Paulo-Rio de Janeiro (pp.185-198). Campinas, Brasil: Puccamp.

Fix, M. (2009). Uma ponte para a especulação - ou a arte da renda na montagem de uma cidade "global". Caderno crh, 22(55), 41-64. http://dx.doi.org/10.1590/S010349792009000100003

Harvey, D. (1989). From managerialism to entrepreneurialism: the transformation of urban governance in late capitalism. Geografiska Annaler, 71(1), 3-17. http://dx.doi. org $/ 10.2307 / 490503$

Healey, P. (2003). Collaborative planning in perspective. Planning Theory, 2(2),101-123. https://doi.org/10.1177/14730952030022002

Instituto Brasileiro de Geografia e Estatística (IBGE) (2011). Censo Demográfico 2010: Características da populaçáo e dos domicílios - resultado do universo. Rio de Janeiro, Brasil: Autor.

Instituto Brasileiro de Geografia e Estatística (IBGE) (2017). Estimativas da população residente no Brasil e unidades da federação com data de referência em $1^{\circ}$ de julho de 2017. ftp://ftp. ibge.gov.br/Estimativas_de_Populacao/Estimativas_2017/estimativa_dou_2017.pdf

Klink, J. \& Denaldi, R. (2015). On urban reform, rights and planning challenges in the Brazilian Metropolis. Planning Theory, 15(4), 402-417. https://doi. org/10.1177/1473095215592441

Klink, J. \& Souza, M. B. (2018). De uma economia política das escalas espaciais a uma agenda renovada para os estudos críticos espaciais. Em C. A. Brandão, V. R. Fernández \& L. C. Q. Ribeiro (orgs.), Escalas espaciais, reescalonamentos e estatalidades: Liçōes e desafios para América Latina (pp. 361-397). Rio de Janeiro, Brasil: Letra Capital.

Law-Yone, H. (2007). Another planning theory? Rewriting the meta-narrative. Planning Theory, 6(3), 315-326. https://doi.org/10.1177/1473095207082038

Lei $n^{\circ}$ 10.257, de 10 de julho de 2001. (2001, 11 de julho). Estatuto da Cidade. Regulamenta os Art. 182 e 183 da Constituição Federal, estabelece diretrizes gerais da política urbana, e dá outras providências. Diário Oficial da Uniăo. Brasília, DF, Brasil. 
Lei no 6.184, de 21 de dezembro de 2011. (2011, 21 de dezembro). Dispóe sobre a aprovação do Plano Diretor do Município de São Bernardo do Campo, e dá outras providências. https://leismunicipais.com.br/a1/sp/s/sao-bernardo-do-campo/lei-ordinaria /2011/619/6184/lei-ordinaria-n-6184-2011-dispoe-sobre-a-aprovacao-do-planodiretor-do-municipio-de-sao-bernardo-do-campo-e-da-outras-providencias?q=6.184

Lei $\mathrm{n}^{\circ}$ 6.324, de 19 de dezembro de 2013. (2013, 19 de dezembro). Dispóe sobre a progressividade no tempo, do Imposto sobre a Propriedade Predial e Territorial Urbana - iptu, de imóveis notificados para o parcelamento, edificação ou utilização compulsórios $e$ dá outras providências. https://leismunicipais.com.br/a1/sp/s/sao-bernardo-docampo/lei-ordinaria/2013/633/6324/lei-ordinaria-n-6324-2013-dispoe-sobre-aprogressividade-no-tempo-do-imposto-sobre-a-propriedade-predial-e-territorialurbana-iptu-de-imoveis-notificados-para-o-parcelamento-edificacao-ou-utilizacaocompulsorios-e-da-outras-providencias? $\mathrm{q}=6.324$

Lei no 6.403, de 22 de junho de 2015. (2015, 22 de junho). Aprova a Operação Urbana Consorciada São Bernardo do Campo (ouc/sbc), cria incentivos para sua implementação, institui o grupo de gestão, autoriza a criação de sociedade de economia mista e dá outras providências. https://leismunicipais.com.br/a1/sp/s/sao-bernardo-do-campo/ lei-ordinaria/2015/641/6403/lei-ordinaria-n-6403-2015-aprova-a-operacaourbana-consorciada-sao-bernardo-do-campo-ouc-sbc-cria-incentivos-para-suaimplementacao-institui-o-grupo-de-gestao-autoriza-a-criacao-de-sociedade-deeconomia-mista-e-da-outras-providencias? $\mathrm{q}=6.403$

Maricato, E. (1977). A proletarização do espaço sob a grande indústria: O caso de São Bernardo do Campo na Região da Grande São Paulo. (Dissertação de Mestrado). Universidade de São Paulo, São Paulo, Brasil.

Maricato, E. (2011). O impasse da politica urbana no Brasil. Petrópolis, Brasil: Vozes.

Ministério da Justiça, Secretaria de Assuntos Legislativos \& Instituto de Pesquisa Econômica Aplicada. (2015). Parcelamento, edificação ou utilização compulsórios e iptu progressivo no tempo: Regulação e aplicação (Série Pensando o Direito, no 56). Brasília, DF, Brasil: IPEA. Em http://pensando.mj.gov.br/wp-content/uploads/2015/11/PoD_56_web1.pdf

Oliveira, F. L. \& Biasotto, R. (2011). O acesso à terra urbanizada nos planos diretores brasileiros. Em O. A. dos Santos Jr. \& D. T. Montandon (orgs.). Os planos diretores municipais pós-Estatuto da Cidade: balanço crítico e perspectivas (pp. 57-98). Rio de Janeiro, Brasil: Letra Capital.

Robinson, J. (2010). Cities in a world of cities: The comparative gesture. International Journal of Urban and Regional Studies, 35(1),1-23. https://doi.org/10.1111/j.14682427.2010.00982.x

Rolnik, R. \& Santoro, P. (2013). Zonas Especiais de Interesse Social (ZEIS) em cidades brasileiras: Trajetória recente de implementação de um instrumento de política fundiária. Cambridge, MA: Lincoln Institute of Land Policy.

Royer, L. (2002). Política habitacional no Estado de São Paulo: Estudo sobre a Companhia de Desenvolvimento Habitacionale Urbano, $C D H U$. (Dissertação de mestrado). Universidade de São Paulo, São Paulo, Brasil.

Sader, E. (1988). Quando novos personagens entraram em cena: Experiências, falas e lutas dos trabalhadores da Grande São Paulo, 1970-80. Rio de Janeiro, Brasil: Paz e Terra. 
Santos Jr, O. A. \& Montandon, D. T. (orgs.). (2011). Os planos diretores municipais pós-Estatuto da Cidade: Balanço crítico e perspectivas. Rio de Janeiro, Brasil: Letra Capital.

Prefeitura do Município de São Bernardo do Campo (рмSвC), Secretaria de Planejamento e Economia. (1982). Favelas de São Bernardo do Campo-1982. São Bernardo do Campo, Brasil: Autor.

Prefeitura do Município de São Bernardo do Campo (PMSBC), Secretaria de Habitação. (2010). Plano Local de Habitação de Interesse Social de São Bernardo do Campo - PLHIS: 20102025. São Bernardo do Campo, Brasil: Autor.

Prefeitura do Município de São Bernardo do Campo (pMSBc), Secretaria de Habitação. (2010a). Território de inovação. São Paulo, Brasil: MP.

Prefeitura do Município de São Bernardo do Campo (рмSBc), Secretaria de Planejamento Urbano e Ação Regional. (2016, 23 de dezembro). Relatório de aplicação do Parcelamento, Edificação ou Utilização Compulsórios (PEUC) e do IPTU Progressivo no Tempo: São Bernardo do Campo, 2013-2016. Notícias do Município, n. 1913. Edição especial. Em http://www.saobernardo.sp.gov.br/documents/10181/542859/23_12_2016_ NM_1913_PEUC.pdf/f2f8c5bf-3e83-8e32-2d5a-3859fa1228e6

Souza, M. (2013). Variedades de capitalismo e reescalonamento espacial do Estado no Brasil. (Tese de doutorado). Universidade Estadual de Campinas, Campinas, Brasil.

Stroher, L. (2017). Operaçóes urbanas consorciadas com Cepac: Uma face da constituição do complexo imobiliário-financeiro no Brasil? Cadernos Metrópole, 19(39),455-477. http://dx.doi.org/10.1590/2236-9996.2017-3905. 